\title{
Progressing chemistry education research as a disciplinary field
}

\author{
Keith S. Tabere
}

\begin{abstract}
This article offers a viewpoint regarding the current status of chemistry education research (CER) as a scholarly field within science education, and suggests priorities for future directions of work in the field. The article begins by briefly considering what makes something a discrete field of activity, and what makes such a field 'scientific'. This provides a basis for understanding and evaluating CER, and informs a consideration of imperatives and priorities for progressing the field. In particular, it is suggested one emphasis should be on areas of work which can be considered 'inherent' to CER as they arise from essential aspects of chemistry teaching and learning, and some examples of such inherent research foci (the 'chemist's triplet'; models in chemistry; chemical explanations) are briefly discussed.
\end{abstract}

Keywords: Chemistry education, Inherent disciplinary educational research, Chemist's triplet, Teaching about models and modelling, Epistemological relevance, Scaffolding learning, Teaching about scientific explanations

\section{Introduction: CER as a field}

This article discusses chemistry education research (CER) as a field, and considers both why it is reasonable to consider CER as a discrete field (rather than just a domain within science education research) and how this has implications for both what is considered to count as CER such that not all educational research carried out in chemistry teaching and learning contexts (CTLC) should be considered inherently CER - and for setting priorities in the field. It is argued that a productive scientific field encompasses progressive research programmes (RP), and some suggestions are made for timely RP.

There is a range of indicators that can be used to consider the extent to which an area of activity can be considered a scholarly field (Fensham, 2004), and based on these indicators CER is now well-established as field in its own right. CER has its own international journals (in particular, Chemistry Education Research and Practice and the Journal of Chemical Education) and regular conference series; there has been a stream of scholarly books on the subject from major publishers, and there is now a specialised book series (Advances in Chemistry Education, published by the Royal Society of Chemistry). There are academics with chairs in the subject, who lead

Correspondence: kst24@cam.ac.uk

Science Education Centre, Faculty of Education, University of Cambridge, 184 Hills Road, Cambridge, England CB2 8PQ, UK research groups focused on chemistry education, and offer specialist doctoral training.

A field needs to be focused on some sphere of activity or phenomena, and in the case of CER this is the practice of chemistry education. As an area of practice, chemistry education might be generally equated to teaching the curriculum subject 'chemistry'. The core phenomena of interest in educational research are teaching and learning (Pring, 2000), and so logically the primary foci of CER are the teaching and learning of chemistry. The wider scope of CER encompasses areas of enquiry linked to these foci. This would include such matters as the chemistry curriculum (what is set out to be taught and learnt; how disciplinary chemical knowledge is represented in the curriculum); how learning of chemistry is assessed; the disciplinespecific aspects of how teachers are prepared for and developed in their work; the design of teaching resources (such as textbooks and digital tools) that represent chemical knowledge in ways informed by knowledge of human learning processes or to support particular pedagogies.

Teaching is activity that is intended to bring about some specific learning. The notion of (specifically) chemistry teaching therefore has most traction in a context where there is a formal curriculum having 'strong classification', that is where the curriculum is divided into clearly distinguished subjects with identifiable areas of content (Sadovnik, 1991). This is worth noting, both 
because there has historically been debate on the place of discrete sciences, versus integrated or coordinated science in the curriculum at school level (Jenkins, 2007), and because in recent years the notion of 'STEM' (science, technology, engineering and mathematics) has shifted from being mainly seen as a label for a grouping of (discrete but) related disciplines, to a recognised curriculum area, and potentially indeed a curriculum subject, in the school curriculum (Chesky \& Wolfmeyer, 2015). That is, in some national contexts STEM remains largely a construct offering a convenient branding for a strategic alliance of those wishing to raise funding support for, and public awareness of the importance of, the sciences and related areas. Yet, in other contexts the traditional boundaries between the natural sciences, and between pure and applied science, are being fundamentally questioned both in terms of science practice and science education.

In such a context, CER may not be understood as purely focused on teaching and learning in classes formally labelled chemistry, as the teaching and learning of chemical topics (e.g., acids), and specific concepts (e.g., oxidation) can occur in the context of 'science' lessons - or indeed STEM classes, or even within the context of curriculum offerings based around interdisciplinary projects that do not explicitly acknowledge traditional subjects (Rennie, Venville, \& Wallace, 2012), or less formal making and tinkering activities where STEM knowledge might be developed on a just-in-time basis (Bevan, Gutwill, Petrich, \& Wilkinson, 2015). Yet this raises the question: why consider teaching these topics in such contexts as chemistry teaching (and so within the remit of CER) rather than science teaching or STEM teaching, or just teaching.

There is also a criticism that the science taught in formal education systems is often learned as a set of discrete topics, whereas one core metaphysical commitment of science is to seek overarching ideas and superordinate concepts that can subsume previously discrete notions (Taber, 2006). This raises the question of whether compartmentalisation of the curriculum is a barrier to students linking up their learning (Taber, 2018a) both within and across subject divides.

Such considerations raise an existential challenge to CER as a field. There is a very well established field of science education (Fensham, 2004), so it might be asked whether CER is any more than just a term covering those studies falling within science education research (SER) where the material being taught happens to be chemical. Unless there is a case to be made in response to such a challenge, CER might be seen to be simply one convenient administrative category when considering studies carried out within SER, rather than something with its own character.

Indeed, there is a strong argument to be made that the recognition of CER, and PER (physics education research), etcetera, as discrete fields owes much to the work done in higher education by researchers from within university science departments and faculties. In that context CER seems a natural category for those employed by chemistry departments - and having little opportunity to come into direct contact with teaching and learning beyond that context. That rationale offers little to those primarily concerned with teaching of school chemistry.

\section{CER as a compound of its elements, not a mixture}

Another argument that has been made is that much research that takes place in chemistry teaching and learning contexts (CTLC) is addressing general educational questions, where the choice of the particular study context may be little more than a matter of convenience, or reflect the professional concerns of practitioners enquiring into their practice to see if they can fruitfully apply recommended innovations in their own teaching. That is, although the work is carried out in a chemistry classroom or some other CTLC, that offers little more than a backdrop to an examination of some general educational focus: for example, about how best to organise a mixedability class into productive working groups. These are questions where the findings from one classroom may not automatically generalise to other classrooms, but where the CTLC is only one potentially relevant variable among many (age of students; gender; diversity of school population in terms of socio-economic status; proportion of students accessing the learning in a second or additional language; etc.)

This type of study has been labelled as 'collateral' CER (Taber, 2013b). By contrast, 'embedded' CER (Taber, 2013b) goes beyond this by carefully linking particular aspects of the specific subject matter being taught to the general educational issue - for example, not just how to implement a flipped learning approach in this class (which happens to be a first year undergraduate chemistry course), but how to best profit from the affordances of flipped learning when introducing the topic of transition metal complexes (or the Nernst equation, or whatever) given the particular challenges in teaching and learning that material.

An inherent assumption here is that the outcomes of the research are in a substantive sense dependent on teaching that is informed by the specialist knowledge about teaching and learning of specific material that a subject specialist teacher brings to the classroom: that is, the pedagogical content knowledge (PCK) (Kind, 2009) that evolves as a kind of meta-knowledge formed from a hybridisation of subject knowledge and general pedagogic knowledge, and developed through testing out in classroom practice (Taber, 2018b). PCK is not just a mixture or assemblage of subject and pedagogic knowledge, but something new, formed by 'reacting' these through planning, teaching, and evaluating classes. 
An interesting thought experiment to distinguish embedded CER from collateral CER might be to consider a CER research report where every mention of chemistry, particular chemical topics, specific chemical concepts, etcetera, has been redacted; and then to ask the question whether the (now non-disciplinary-specific) conclusions of the study can still be considered robust. If we judged the study offered convincing implications independent of the disciplinary context (which is no longer available to a reader seeking to evaluate the redacted manuscript), then these have not been bound to the specific challenges of teaching the subject matter. Such research could be considered metaphorically a mixture of educational research and chemistry, as these components can be separated out, rather than a compound that has its own characteristic CER properties.

Of course, embedded CER might not be so different in kind than embedded PER or other educational research where the specifics of the curriculum context are intrinsic to the research. There may be differences in detail in how teachers can, for example, usefully apply Bloom's taxonomy to planning different lessons (Anderson \& Krathwohl, 2001), but perhaps (and this may be considered an empirical question) those differences in detail are no greater when (a) comparing the teaching of homologous series with the teaching of electromagnetic induction, or with the teaching about the causes of the industrial revolution; than when (b) comparing the teaching of homologous series with teaching about Lewis acid theory, or with teaching about electronegativity. If that were so, then CER still seems little more than a bureaucratic label, albeit for (i) findings that are contingent on the peculiarities of specific disciplinary content (where that content falls within the discipline of chemistry), rather than (ii) findings presented as widely generalisable to different teaching contexts, which just happen to derive from a CTLC.

\section{Inherent disciplinary educational research}

Yet, it is also the case that a discipline such as chemistry does present its own particular challenges that are somewhat distinct from those found in other disciplines, and which are also widely relevant when teaching and learning beyond a single teaching topic and across the discipline. I will here suggest two such 'essential' foci for 'inherent' CER (Taber, 2013b) that explores issues intrinsic to the teaching of the discipline.

Johnstone (1982) mooted the idea that chemistry teaching was especially challenging because it asked students to think - often at the same time - about the macroscopic (bench-scale) phenomenon, the molecular level structure of matter, and the specialised forms of representation used in chemistry. The so-called chemist's triplet has become a particular core concern in chemistry education where it has been recognised as critically important in teaching and learning the subject, and so has become a key focus of research and scholarship (Taber, 2013a; Talanquer, 2011). This issue is important across the teaching of many topics within chemistry, but does not apply directly in other disciplines. Johnstone suggested biology and physics faced similar, although not identical, issues, but his arguments have not been seen as so centrally important in teaching those subjects. In particular, the ubiquitous use of the 'chemical language' of formulae and equations to bridge between the molar and molecular levels in explaining chemical phenomena is characteristic of much chemistry teaching (Taber, 2009).

Another issue that is especially important in chemistry relates to the nature of models met in learning the subject. Again, this seems to be an especially pertinent issue for chemistry education, where an understanding of the nature of models and modelling (both those used in chemistry itself, and the various teaching models employed to introduce abstract chemical ideas) is essential to make sense of the concepts of the subject and make good progress in learning (Taber, 2010). Models of atomic and molecular structure, mathematical models, notions of ideal gases, typologies (such as metal and non-metal, types of bonding), metaphorical language (sharing electrons, electrophilic attack, etc.) and historically shifting concepts (oxidation, acid, etc.), and so forth, are ubiquitous, and much of this conceptual apparatus has become second nature for the teacher - for whom, subjectively, a double bond has likely become as real an object as a conical flask. Supporting students to develop the epistemological sophistication to make sense of the concepts of chemistry, and to keep in mind the ontological status of the 'objects' they meet in their studies (e.g., dative bonds, electron deficient compounds, antiaromaticity, transition states, hybridised atomic orbitals ...) is a key challenge for the CER community (Taber, 2019a). Models and modelling in science and teaching is certainly an important theme across SER (Gilbert, 2004), but has proved especially vexing in chemistry teaching, and would seem a clear imperative for research in CER.

\section{CER as a scientific research field}

There are many recognised academic fields across the natural sciences, social sciences, humanities and arts. Education as an academic subject is something of a scavenger founded on other subjects (usually considered to include philosophy, history, psychology and sociology, and these days increasingly economics), intimately tied with the wide range of disciplines that are found in curriculum (such as, inter alia, chemistry), and regularly borrowing ideas and perspectives widely from other areas of the academy. Educational research is often considered essentially social science, but the diversity of research and scholarship carried 
out in some education faculties spans a full range from pure experiments to literary criticism.

Chemistry education is clearly not a natural science as it focuses on social, not natural, phenomena, but scholars working in CER generally consider they are seeking to be scientific in their work. In natural sciences, such as chemistry, research traditions develop where researchers are inducted into the norms of the research field, and mature traditions of work can be characterised by a disciplinary matrix (Kuhn, 1970, 1974/1977) that can include ontological commitments (e.g., matter is comprised of submicroscopic quanticles) and epistemological and methodological standards (such the forms of laboratory technique and analysis considered suitable in a line of work) as well as conventions relating to how arguments should be presented, use of technical vocabulary and specialised forms of representation, and such matters as which journals and conferences are appropriate targets for research outputs.

Compared with chemistry, CER admits a wide range of theoretical perspectives (deriving from the learning sciences, sociology, etc.) and methodological approaches. That could be considered a sign of a lack of maturity in the field, but could also, alternatively, reflect the complexity, and context-dependence, of the core phenomena of teaching and learning (Taber, 2014). There are guidelines on what makes educational research scientific (National Research Council Committee on Scientific Principles for Educational Research, 2002) which acknowledge the diversity of approaches possible, subject to meeting quality criteria in terms of research design and execution.

One helpful idea from history and philosophy of science is the observation that research in natural science disciplines such as chemistry becomes organised into research programmes (RP) that have inherent and explicit core commitments (to what is to be taken for granted; to what classes of research questions are to be addressed) shared by researchers working in that tradition, and which provide sufficient commonality to allow work from different scholars and research groups to iteratively build up a better understanding (Lakatos, 1970). These RP are not exclusive, in the sense that alternative parallel programmes taking different approaches to explore the same phenomena are possible, but the agreement on 'hard core' assumptions and research purposes allows those working within a particular RP to evaluate whether it remains a 'progressive' programme.

A progressive RP is one where empirical and theoretical work are feeding into each other to develop better understandings (as opposed to, for example, where theory is simply being adjusted after the fact to 'save the phenomena' as empirical tests fail to demonstrate predicted outcomes). Within this model, the scientist may sometimes 'quarantine' anomalous results (Lakatos, 1970), that is, acknowledge they challenge current theory, but choose to put this aside as a problem to be addressed later - something a strictly falsificationalist model (Popper, 1989) would not allow - against a global judgement that the programme is, on balance, making progress.

\section{Striking a balance in structuring CER as a field}

The historian of science Thomas Kuhn (1959/1977) referred to the 'essential tension' in science between (a) the priority of the established research traditions (a priority often reflected in academic appointments and promotions and, in particular, awards of research grants), which require scientists to be disciplined in following lines of work that have previously been found fruitful, and (b) the importance of the creative insight which, recognising which anomalies are potentially significant, enables a completely new conceptualisation that might revolutionise a field. Hegemony can be an impediment to progress in science (Josephson, 1992), just as elsewhere, but even if the creative research scientist adopts something of the mentality of bricolage, seeking to find what works in relation to a new problem (Feyerabend, 1975/1988; Kincheloe, 2005), scientific fields are largely characterised by structured research programmes.

The present author's experience of having edited a research journal dedicated to CER for over 7 years suggests that anyone reviewing CER today would find considerable diversity in (a) the specific foci of research, (b) theoretical perspectives used to conceptualise that research, and (c) methodological strategies and tactics adopted (e.g., Teo, Goh, \& Yeo, 2014). It is clearly important that CER remains open to new ideas, new insights, new directions of research (Sevian, 2017), but there is also a case to be made for adopting a more programmatic approach that allows studies to share sufficient groundwork to build iteratively on each other (Taber, 2017).

\section{Recommendations for the field}

The danger I have sought to highlight in this article, is that CER may largely be (or become) a label for education research studies that are either only addressing general questions and happen to be undertaken in CTLC, or embedded studies that address specifics of teaching and learning particular chemistry content, but which are tied to teaching that topic, at that academic level, with limited scope for generalisation beyond the specific context.

Two recommendations that follow from the analysis are offered here. The first is to encourage work that is 'inherent' CER because it addresses issues especially, indeed essentially, important across teaching chemistry. The second relates to identifying the programmes of work that link to the major challenges that arise in teaching and learning chemistry. 


\section{Identifying inherent CER}

I have already mentioned two examples reflecting major challenges faced by practitioners: the so-called 'chemist's triplet' and the ubiquity of models in teaching and learning chemistry. I briefly revisit these, and suggest another related focus for research attention (chemical explanations).

\section{Applying the chemist's triplet}

One important RP concerns understanding how the core CER notion of the chemist's triplet can be used to better conceptualise learning difficulties and plan curriculum and teaching. Johnstone (1982) highlighted how the triplet put a burden on students, but the nature of chemistry suggests that authentic chemistry education needs to often simultaneously employ the three aspects of the triplet. There is a good deal of groundwork in this area (Gilbert \& Treagust, 2009), but it is questionable whether this has yet fed widely into informing classroom practice.

Johnstone's initial characterisation of three levels has the elegance of a simple formulation that teachers can readily appreciate and relate to. Most commonly, the triplet is understood in terms of Johnstone's (1982) original macroscopic and submicrosopic (as well as the symbolic representational) levels, but Talanquer (2011, p. 180) emphasises the contrast between the 'descriptive and functional' level "at which phenomena are experienced, observed and described" and the 'explanatory' level "at which phenomena are explained”. A slightly different reconceptualisation sees the phenomena observed (and often perceived by learners in relation to everyday ideas, e.g., burning, disappearing) to be re-described both at the macroscopic level in terms of technical chemical concepts and categories (e.g., combustion: reaction with oxygen, dissolving), and then in terms of the explanatory models of the structure of matter at the submicroscopic / nanoscale (Taber, 2013a). In this version, the symbolic is not seen as a discrete level, but as representing, and sometimes bridging explanations across, the two levels of chemical description. As these brief accounts suggest, there are different ways the 'levels' - and how they link to models, theories, and explanations - can be understood. There is clearly scope for more enquiry into how these ideas can best support chemistry teaching.

\section{Making sense of models and representations}

The second issue concerns the high frequency of models and related devices (e.g., metaphors) met in learning chemistry. Again, an authentic chemistry education (that reflects the disciplinary practices of the subject) cannot proceed by excluding these, so work is needed to support learners in developing more 'epistemological nous' (for example, not seeing atomic models as realistic) and applying metacognition to critically examine their learning (e.g., asking critically what does 'sharing' electrons mean?)
Perhaps, teachers might initially question the wisdom here, but we would recognise progress when students come to regularly respond to teaching by asking difficult questions such as (i) how can the particles be touching in a solid when the spaces between them change with heating or cooling; (ii) why do the protons in a nucleus not repel each other so much that the nucleus disintegrates; (iii) in what sense, exactly, is a methane molecule a tetrahedron (Taber, 2019a)?

\section{Explanation}

Another potential focus for productive research is the theme of explanations, and this might be an area that could be linked to the developing focus on learning progressions in chemistry (Sevian \& Talanquer, 2014). Explanation is core to chemistry (and often links to the triplet, and to the various models used in the subject).

In recent years there has been considerable focus on the process of scientific argumentation and how this can be modelled in teaching (Erduran, Simon, \& Osborne, 2004; Newton, Driver, \& Osborne, 1999). However the related, and equally core, notion of explanation has had much less attention, with very little work looking at the nature of students' explanations (Taber \& Watts, 2000) or how students can critique or construct explanations (Taber, 2007). This would seem to be an important area where there is much potential for useful research. Ideally this might be the focus of learning progression research (Alonzo \& Gotwals, 2012), to first explore typical levels of student competencies at different grades, and then to inform curriculum design and teaching that can support progression.

\section{Responding to key challenges in chemistry education}

There are many other potential areas of work in CER that can increase our understanding and so better support teaching. Probably the two biggest challenges to chemistry education, especially where chemistry is not an elective subject but one all students are expected to study, relate to relevance and difficulty.

\section{Making chemistry relevant to all}

Chemistry is obviously (to a chemist) relevant to everything around us in the material world, but, as a science, chemistry is concerned with substances and their properties and interactions - and that is already an abstraction when very few of the materials young people come into contact with in everyday life are pure substances. There is a challenge therefore to make chemistry relevant (Eilks \& Hofstein, 2015). One response might be not to teach chemistry as such in the lower grades (e.g., up to age 12 or 13 ?), but rather a form of material science that would be more context-based (Bennett, Hogarth, \& Lubben, 2003) 
and enquiry-based (Schwab, 1962) - possibly linked to environmental and socio-scientific issues (Zeidler, 2014) and which would provide both practical experience and background knowledge to be used as the foundations of a formal study of chemistry in later grades.

Another suggestion (perhaps once students progress to those later grades) is to use practical work as a means of introducing phenomena to be explored and explained, and so to provide epistemic relevance to the concepts of chemistry (Taber, 2015), given that more traditional approaches teach scientific concepts that are in effect answers to historical questions that most students have never had reason to ask. This might be a less efficient (i.e., slower) approach to teaching canonical concepts, but may be a more authentic reflection of chemistry as science, and a way of engaging students' imaginations to develop rich conceptualisations that may ultimately offer better foundations for learning canonical models and theories.

\section{Scaffolding learning}

That chemistry is a highly theoretical subject, as well as a laboratory subject, makes the introduction of a good deal of abstract material that many students find challenging, unavoidable. There is already a great deal of work exploring aspects of learners' difficulties in understanding chemical concepts, and in particular their alternative conceptions and frameworks in the subject (Kind, 2004), and why these conceptions occur (Taber, 2002, 2019a). There is also work on supporting teachers by providing classroom diagnostic tools to identify student thinking (Treagust, 2006). Yet there is more to do, especially in supporting teachers to adopt research-informed teaching within existing curriculum and institutional constraints.

One notion that has been adopted in school teaching is that of 'scaffolding' as a strategy for supporting learners to master challenging ideas or skills. In practice, however, this sometimes amounts to little more than applying such common pedagogic tactics as breaking complex material down, offering students support in the form of hand-outs and hints, or expecting group-work to provide sufficient peer support. The idea of scaffolding, however, derives from a particular perspective based on the works of Vygotsky (1978), that offers potential for providing more customised, individualised, support for students given sufficient information about their particular characteristic as learners (Taber, 2018c). In principle, then, scaffolding could be a very powerful strategy, but needs to be applied in relation to both the particular learners and subject matter. Research to explore how viable the approach is when used by busy teachers with large classes could be very valuable, but also challenging to carry out.

\section{Conclusions}

Space here does not allow the development or augmentation of these examples, but hopefully they sufficiently make the point: for CER to progress as a field (i) it needs to take as strong foci the particular issues of teaching and learning chemistry, that is, those issues that are specific, or especially pronounced, or at least need to be understood within particular contexts, in the practice of chemistry teaching; and (ii) there needs to be a programmatic flavour to much of the work undertaken - to enable ready communication between researchers; to facilitate studies to clearly build iteratively on what has gone before; and to allow the CER community to make evaluations of which lines of work are progressive, and so worthy of attention and resourcing.

This is not an argument for a 'closed-shop' with exclusive programmes of research, nor for excluding the maverick or idiosyncratic from the field. CER benefits from cross-fertilisation with other disciplines, and the 'essential tension' needs to be held in balance. This article is certainly not suggesting a need for a regimentation of research moderated by intellectual thought police, but rather that those leading the field should offer heuristic guidance to channel the most promising directions for enquiry. For any field to remain viable there must be a semblance of structure and order perceived as standing out from the background of diverse activity. CER is not a field of chemistry in the way that transition metal chemistry is, or organometallic chemistry is, or photochemistry is: its primary phenomena are social and psychological (teaching, learning), not chemical.

This can present challenges for CER researchers. For those transitioning from exclusively undertaking research in the natural sciences, this can require a substantive reorientation in relation to both the nature of knowledge claims and the kinds of approaches that need to be applied. As two obvious differences: natural materials subject to investigation in the chemistry laboratory neither expect a duty of care from researchers (we do not need to take precautions to protect the integrity of strips of magnesium or aliquots of sulphuric acid that are subject to laboratory manipulations), nor change their properties in response to being selected as the sample to be tested or because they suspect they know what the researcher is looking for. By contrast, people are entitled to expect researchers to both avoid doing anything likely to harm them (which includes disrupting their learning), and to take their preferences (such as declining to participate) into account; and may also have their attitudes and motivations (and so their responses) modified by the attention of researchers and/or tacitly communicated researcher expectations (Taber, 2019b).

For those based in chemistry or other natural science departments, another challenge can be the attitudes and 
perceptions of colleagues. The norms of CER may not be appreciated by colleagues with no background in research in the social sciences, which are often considered to be 'softer' (and so by implication less rigorous or demanding) than the 'hard' sciences. Commitment to CER enquiries may not always be accepted as a valid alternative to chemistry research, especially in a context where university research is evaluated along disciplinary lines and CER publications are considered 'education' rather than 'chemistry' outputs.

For CER to count as 'disciplinary' research it needs to be an identifiable discipline in its own right and not simply borrow credence from being associated with the discipline of chemistry. I hope this article has offered some ideas regarding how this can be maintained and developed in practice.

\section{Abbreviations}

CER: Chemistry education research; CTLC: Chemistry teaching and learning contexts; PCK: Pedagogical content knowledge; PER: Physics education research; RP: Research programmes; SER: Science education research; STEM: Science, technology, engineering and mathematics

\section{Acknowledgements}

Not applicable.

\section{Author's contributions}

KST is the sole author of this article. The author read and approved the final manuscript.

\section{Author's information}

Keith S. Taber is Professor of Science Education at the University of Cambridge. He has been (2011-2018) the editor of the journal Chemistry Education Research and Practice, and he is the Editor-in-Chief of the Royal Society of Chemistry book series Advances in Chemistry Education.

\section{Availability of data and materials}

Not applicable.

\section{Competing interests}

The author declares that s/he has no competing interests.

Received: 17 April 2019 Accepted: 22 October 2019

Published online: 28 November 2019

\section{References}

Alonzo, A. C., \& Gotwals, A. W. (Eds.) (2012). Learning progressions in science Current challenges and future directions. Rotterdam: Sense Publishers.

Anderson, L. W., \& Krathwohl, D. R. (2001). A taxonomy for learning, teaching and assessing: A revision of Bloom's taxonomy of educational objectives. New York: Longman.

Bennett, J., Hogarth, S., \& Lubben, F. (2003). A systematic review of the effects of context-based and Science-Technology-Society (STS) approaches in the teaching of secondary science: Review conducted by the TTA-supported science review group. London: EPPI-Centre, Social Science Research Unit, Institute of Education, University of London.

Bevan, B., Gutwill, J. P., Petrich, M., \& Wilkinson, K. (2015). Learning through STEMrich tinkering: Findings from a jointly negotiated research project taken up in practice. Science Education, 99(1), 98-120. https://doi.org/10.1002/sce.21151.

Chesky, N. Z., \& Wolfmeyer, M. R. (2015). Philosophy of STEM education: A critical investigation. New York: Palgrave Macmillan.

Eilks, l., \& Hofstein, A. (Eds.) (2015). Relevant chemistry education: From theory to practice. Rotterdam: Sense Publishers.

Erduran, S., Simon, S., \& Osborne, J. (2004). TAPping into argumentation: Developments in the application of Toulmin's argument pattern for studying science discourse. Science Education, 88(6), 915-933.
Fensham, P. J. (2004). Defining an identity: The evolution of science education as a field of research. Dordrecht: Kluwer Academic Publishers.

Feyerabend, P. (1975/1988). Against method (Revised ed.). London: Verso.

Gilbert, J. K. (2004). Models and modelling: Routes to more authentic science education. International Journal of Science and Mathematics Education, 2(2), 115-130.

Gilbert, J. K., \& Treagust, D. F. (Eds.) (2009). Multiple representations in chemical education. Dordrecht: Springer.

Jenkins, E. W. (2007). School science: a questionable construct? Journal of Curriculum Studies, 39(3), 265-282.

Johnstone, A. H. (1982). Macro- and microchemistry. School Science Review, 64(227), 377-379.

Josephson, P. R. (1992). Soviet scientists and the state: Politics, ideology, and fundamental research from Stalin to Gorbachev. Social Research, 59(3), 589-614.

Kincheloe, J. L. (2005). On to the next level: Continuing the conceptualization of the Bricolage. Qualitative Inquiry, 11(3), 323-350. https://doi.org/10.1177/ 1077800405275056

Kind, V. (2004). Beyond appearances: Students' misconceptions about basic chemical ideas, (2nd ed., ). London: Royal Society of Chemistry.

Kind, V. (2009). Pedagogical content knowledge in science education: Perspectives and potential for progress. Studies in Science Education, 45(2), 169-204. https://doi.org/10.1080/03057260903142285.

Kuhn, T. S. (1959/1977). The essential tension: Tradition and innovation in scientific research. In T. S. Kuhn (Ed.), The essential tension: Selected studies in scientific tradition and change, (pp. 225-239). Chicago: University of Chicago Press.

Kuhn, T. S. (1970). The structure of scientific revolutions, (2nd ed., ). Chicago: University of Chicago.

Kuhn, T. S. (1974/1977). Second thoughts on paradigms. In T. S. Kuhn (Ed.), The essential tension: Selected studies in scientific tradition and change, (pp. 293319). Chicago: University of Chicago Press.

Lakatos, I. (1970). Falsification and the methodology of scientific research programmes. In I. Lakatos, \& A. Musgrove (Eds.), Criticism and the growth of knowledge, (pp. 91-196). Cambridge: Cambridge University Press.

National Research Council Committee on Scientific Principles for Educational Research (2002). Scientific research in education. Washington DC: National Academies Press

Newton, P., Driver, R., \& Osborne, J. (1999). The place of argumentation in the pedagogy of school science. International Journal of Science Education, 21(5), 553-576.

Popper, K. R. (1989). Conjectures and refutations: The growth of scientific knowledge, (5th ed., ). London: Routledge.

Pring, R. (2000). Philosophy of educational research. London: Continuum.

Rennie, L. J., Venville, G., \& Wallace, J. (2012). Knowledge that counts in a global community: Ex/poring the contribution of integrated curriculum. Abingdon: Routledge.

Sadovnik, A. R. (1991). Basil Bernstein's theory of pedagogic practice: A structuralist approach. Sociology of Education, 64(1), 48-63. https://doi.org/10. 2307/2112891.

Schwab, J. J. (1962). The teaching of science as enquiry (the Inglis lecture, 1961). In J. J. Schwab, \& P. F. Brandwein (Eds.), The teaching of science. Cambridge: Harvard Univewrsity Press.

Sevian, H. (2017). What is chemistry education research (CER)? - letter to the editor. Educación Química, 28(4), 195-308.

Sevian, H., \& Talanquer, V. (2014). Rethinking chemistry: A learning progression on chemical thinking. Chemistry Education Research and Practice, 15(1), 10-23. https://doi.org/10.1039/c3rp00111c.

Taber, K. S. (2002). Chemical misconceptions - prevention, diagnosis and cure. London: Royal Society of Chemistry.

Taber, K. S. (2006). Conceptual integration: A demarcation criterion for science education? Physics Education, 41(4), 286-287.

Taber, K. S. (2007). Choice for the gifted: Lessons from teaching about scientific explanations. In K. S. Taber (Ed.), Science education for gifted learners, (pp. 158-171). London: Routledge.

Taber, K. S. (2009). Learning at the symbolic level. In J. K. Gilbert, \& D. F. Treagust (Eds.), Multiple representations in chemical education, (pp. 75-108). Dordrecht: Springer.

Taber, K. S. (2010). Straw men and false dichotomies: Overcoming philosophical confusion in chemical education. Journal of Chemical Education, 87(5), 552-558. https://doi.org/10.1021/ed8001623.

Taber, K. S. (2013a). Revisiting the chemistry triplet: Drawing upon the nature of chemical knowledge and the psychology of learning to inform chemistry 
education. Chemistry Education Research and Practice, 14(2), 156-168. https:// doi.org/10.1039/C3RP00012E.

Taber, K. S. (2013b). Three levels of chemistry educational research. Chemistry Education Research and Practice, 14(2), 151-155.

Taber, K. S. (2014). Methodological issues in science education research: A perspective from the philosophy of science. In M. R. Matthews (Ed.), International Handbook of Research in History, Philosophy and Science Teaching, (pp. 1839-1893). Netherlands: Springer.

Taber, K. S. (2015). Epistemic relevance and learning chemistry in an academic context. In I. Eilks, \& A. Hofstein (Eds.), Relevant chemistry education: From theory to practice, (pp. 79-100). Rotterdam: Sense Publishers.

Taber, K. S. (2017). Is CER best considered a discipline or a field of study? Reply to Hannah Sevian's comment. Educacion Quimica, 28, 304-306. https://doi.org/ 10.1016/j.eq.2017.06.003.

Taber, K. S. (2018a). Knowledge sans frontières? Conceptualising STEM in the curriculum to facilitate creativity and knowledge integration. In K. S. Taber, M. Sumida, \& L. McClure (Eds.), Teaching gifted learners in STEM subjects: Developing talent in science, technology, engineering and mathematics, (pp. 1-19). Abingdon: Routledge.

Taber, K. S. (2018b). Masterclass in science education: Transforming teaching and learning. London: Bloomsbury.

Taber, K. S. (2018c). Scaffolding learning: Principles for effective teaching and the design of classroom resources. In M. Abend (Ed.), Effective teaching and learning: Perspectives, strategies and implementation, (pp. 1-43). New York: Nova Science Publishers.

Taber, K. S. (2019a). The nature of the chemical concept: Constructing chemical knowledge in teaching and learning. Cambridge: Royal Society of Chemistry.

Taber, K. S. (2019b). Experimental research into teaching innovations: responding to methodological and ethical challenges. Studies in Science Education, 55(1), 69-119. https://doi.org/10.1080/03057267.2019.1658058.

Taber, K. S., \& Watts, M. (2000). Learners' explanations for chemical phenomena. Chemistry Education: Research and Practice in Europe, 1(3), 329-353.

Talanquer, V. (2011). Macro, submicro, and symbolic: The many faces of the chemistry "triplet". International Journal of Science Education, 33(2), 179-195. https://doi.org/10.1080/09500690903386435.

Teo, T. W., Goh, M. T., \& Yeo, L. W. (2014). Chemistry education research trends: 2004-2013. Chemistry Education Research and Practice, 15, 470-487. https:// doi.org/10.1039/C4RP00104D.

Treagust, D. F. (2006). Diagnostic assessment in science as a means to improving teaching, learning and retention. Paper presented at the UniServe Science Assessment Symposium Proceedings. http://openjournals.library.usyd.edu.au/ index.php/IISME/article/view/6375

Vygotsky, L. S. (1978). Mind in society: The development of higher psychological processes. Cambridge: Harvard University Press.

Zeidler, D. L. (2014). Socioscientific issues as a curriculum emphasis: Theory, research, and practice. In N. G. Lederman, \& S. K. Abell (Eds.), Handbook of research on science education, (vol. 2, pp. 697-726). New York: Routledge.

\section{Publisher's Note}

Springer Nature remains neutral with regard to jurisdictional claims in published maps and institutional affiliations.

\section{Submit your manuscript to a SpringerOpen ${ }^{\circ}$ journal and benefit from:}

- Convenient online submission

- Rigorous peer review

- Open access: articles freely available online

- High visibility within the field

- Retaining the copyright to your article

Submit your next manuscript at $\boldsymbol{\triangleright}$ springeropen.com 